\title{
Melanogenesis in uveal melanoma cells: Effect of argan oil
}

\author{
NUNZIA CAPORARELLO ${ }^{1}$, MELANIA OLIVIERI $^{1}$, MARTINA CRISTALDI $^{1}$, DARIO RUSCIANO $^{2}$, \\ GABRIELLA LUPO $^{1}$ and CARMELINA DANIELA ANFUSO ${ }^{1}$ \\ ${ }^{1}$ Department of Biomedical and Biotechnological Sciences, Section of Medical Biochemistry, \\ University of Catania, I-95123 Catania; ${ }^{2}$ Sooft Italia S.p.A., Rome, Italy
}

Received April 11, 2017; Accepted July 26, 2017

DOI: $10.3892 / \mathrm{ijmm} .2017 .3104$

\begin{abstract}
The mechanisms underlying cutaneous melanogenesis have been widely studied; however, very little is known about uveal melanogenesis. Melanin is normally produced by uveal melanocytes and gives the color to the iris. A derangement from this normal production may occur, for instance, by iatrogenic events, such as glaucoma therapy with prostaglandins that may enhance cutaneous and iris pigmentation. In this study, we investigated the mechanisms that regulate uveal melanogenesis in human uveal melanoma cells (92.1) and murine cutaneous melanoma cells (B16-F1). In the first part of the study, we compared the effects of known cutaneous pigmenting agents on the B16-F1 and 92.1 cells, showing an opposite response of the two cell lines. Subsequently, using argan oil, a known depigmenting agent for murine cutaneous melanoma cells, on 92.1 cells, we found that in these cells, it also functioned as an inhibitor of melanogenesis and tyrosinase expression. From a molecular perspective, treatment of the 92.1 cells with argan oil decreased melanogenesis-associated transcription factor (MITF) gene expression by inducing MITF phosphorylation at Ser73, thus leading to MITF ubiquitination and disposal. It also led to the downregulation of the extracellular signal-regulated kinase (ERK)1/2 and Akt pathways, also known to be involved in cutaneous melanogenesis, although with an opposing function. Taken together, our data indicate that: i) some differences exist in the regulation of melanogenesis between cutaneous and uveal melanoma cells; and ii) argan oil exerts a depigmenting effect on 92.1 cells through its action on the ERK1/2 and Akt pathways.
\end{abstract}

\section{Introduction}

Melanocytes, melanin-producing cells, originate from embryonic neural crest cells (NCCs) (1). They are found in the epidermis, hair and iris, but are also distributed in the nervous

Correspondence to: Professor Gabriella Lupo, Department of Biomedical and Biotechnological Sciences, Section of Medical Biochemistry, University of Catania, Biological Tower, via S. Sofia 97, I-95123 Catania, Italy

E-mail: gabriella.lupo@unict.it

Key words: iris, melanogenesis, argan oil, Akt, ERK1/2 system, inner ear and heart $(2,3)$. Other types of cells able to produce melanin are cells of the retinal pigmented epithelium, the epithelia of the iris and the ciliary body in the eye, as well as adipocytes and some neurons $(4,5)$.

The most important inducer of melanogenesis is the $\alpha$-melanocyte-stimulating hormone ( $\alpha$-MSH), which exerts its effects through melanocortin receptor 1(MC1R) (6). Melanin biosynthesis is catalyzed by tyrosinase as the rate-limiting enzyme, together with tyrosinase-related proteins 1 and 2 (7). The main transcriptional activator of these melanogenic enzymes is the microphthalmia transcription factor, melanogenesis-associated transcription factor (MITF) (8), the activity of which may be regulated by several signaling pathways. It is well known that the phosphoinositide 3-kinase (PI3K)/Akt pathway negatively regulates the expression of MITF (9), while the activation of extracellular signal-regulated kinase (ERK) phosphorylates MITF at Ser73, thus leading to its ubiquitination and degradation (10).

The regulation of melanogenesis in cutaneous melanocytes has been extensively investigated (11-13); however, little is known about the role of $\alpha$-MSH and MC1R in the growth of human uveal melanocytes and melanin production. It has been reported that several cell lines of iridal origin or choroidal melanocytes from human donor eyes exhibit no detectable amount of MC1R and show no response to $\alpha$-MSH treatment, independently from iris color (14). These results suggest a differential regulation of melanogenesis in the area of the eye and may explain the difference in the in vivo functions between cutaneous and uveal melanocytes, such as the tanning response following exposure to solar radiation, that is evident in skin, but not in melanocytes from the iris.

Although it may seem that melanin production is hardly regulated in the adult eye, it has been demonstrated that prostaglandin analogs used for the treatment of elevated intraocular pressure in patients with primary open-angle glaucoma may cause an increase in pigmentation in periocular skin and a spotted iris hyperpigmentation (15).

It has been demonstrated that melanin synthesis can be modulated by various effectors, including mangosteen (Garcinia mangostana) leaf extract (16), baicalein (one of the major flavonoids in Scutellaria baicalensis) (17), Wnts (a large family of secreted glycoproteins that act as ligands to activate receptor-mediated signaling pathways) (18), extract of Angelicae Gigantis Radix (19) and lactoferricin B (a peptide of bovine lactoferrin) (20). Several molecules are known to 
be endowed with lightening activity on cutaneous melanocytes (21), whilst currently no molecules with a similar activity on ocular melanocytes have been described, at least to the best of our knowledge. Argan oil, for instance, is derived from the fruit of Argania spinosa and is widely used in folk medicine and in cosmetics for the treatment of eczema, psoriasis, skin inflammation, to heal burns and wounds, to cure brittle fingernails, and to prevent hair loss and dry hair. Recently, it has been shown that argan oil exerts a depigmenting effect in vitro on mouse cutaneous melanoma cells (22).

Therefore, in this study, we used argan oil to examine melanin biosynthesis and its regulation in iris-derived melanocytes, using melanin content and tyrosinase as markers of melanogenesis, and MITF, ERK1/2 and Akt as markers of its regulation.

\section{Materials and methods}

Chemicals and antibodies. PD98059 (P215), wortmannin (W1628), LY294002 (L9908) and CHAPS (C5849) were purchased from Sigma-Aldrich (St. Louis, MO, USA). Goat polyclonal anti-tyrosinase antibody (Tyrosinase C-19; cat.no.sc-7833) was fromSantaCruzBiotechnology,Inc.(Dallas, TX, USA), rabbit polyclonal anti-phosphorylated MITF at Ser73 antibody (cat. no. SAB4503940) was from Sigma-Aldrich, mouse monoclonal anti- $\beta$-actin antibody (cat. no. MA1-91399) was from Thermo Fisher Scientific (Waltham, MA, USA), and rabbit monoclonal anti-MITF (cat. no. 12590), rabbit polyclonal anti-phosphorylated (cat. no. 9101) and total ERK (cat. no. 9102), rabbit polyclonal anti phosphorylated (cat. no. 9271) and total Akt (cat. no. 9272) antibodies were all from Cell Signaling Technology, Inc. (Beverly, MA, USA). Forskolin was from Sigma-Aldrich (cat. no. F6886). Argan oil (composition shown in Table I) was purchased from Natural Sourcing LLC (Oxford, CT, USA) and used as a fine emulsion in growth medium.

Cell culture. The B16-F1 mouse cutaneous melanoma cells were a kind gift from Dr Vera Cardile (Department of BIOMETEC, University of Catania, Catania, Italy); the cells were routinely cultured as monolayers in Falcon Petri dishes (Lincoln Park, NJ, USA) in a humidified incubator at $37^{\circ} \mathrm{C}$ with DMEM and $10 \%$ FCS. The 92.1 human uveal melanoma cell line was purchased from the Cell Factory-IST (Genoa, Italy) and grown in monolayer cultures in regular RPMI-1640 medium supplemented with $10 \%$ heat-inactivated FBS, $100 \mathrm{IU} / \mathrm{ml}$ penicillin, $100 \mu \mathrm{g} /$ $\mathrm{ml}$ streptomycin and $2 \mathrm{mmol} / \mathrm{l}$ of L-glutamine in a humidified atmosphere $\left(5 \% \mathrm{CO}_{2} / 95 \%\right.$ air $)$ at $37^{\circ} \mathrm{C}$.

Cell viability. Monolayer cultures of 92.1 cells were seeded in 96-well plates at $10^{4}$ cells/well in $0.1 \mathrm{ml}$ of complete culture medium in the absence or in presence of argan oil. To determine cell viability, the 3-[4,5-dimethylthiazol-2-yl]-2,5-diphenyl tetrasodium bromide (MTT) assay was used (Chemicon, Temecula, CA, USA). At the end of the treatment time, the cells in each well were incubated at $37^{\circ} \mathrm{C}$ with additional $0.01 \mathrm{ml}$ MTT $(5 \mathrm{mg} / \mathrm{ml})$ for $4 \mathrm{~h}$; subsequently, $0.1 \mathrm{ml}$ isopropanol in the presence of $20 \mu \mathrm{l}$ of $5 \%$ (w/v) sodium dodecyl sulfate (SDS) in water was added and, after $1 \mathrm{~h}$, the absorbance was measured at $570 \mathrm{~nm}$ in a plate reader (VarioSkan; Thermo Fisher Scientific) $(23,24)$.
Table I. Composition of argan oil used in the experiments.

\begin{tabular}{lc}
\hline Compounds & Amount $(\%)$ \\
\hline Oleic acid & $43-55$ \\
Linoleic acid & $30-38$ \\
Palmitic acid & $11-16$ \\
Stearic acid & $3.5-7$ \\
Linolenic acid & $\leq 0.5$ \\
Arachidonic acid & $\leq 0.5$ \\
Gadoleic acid & $\leq 0.5$ \\
Others & $\leq 0.5$ \\
Unsaponifiables & $0.5-1.5$
\end{tabular}

Melanin content. Melanin content was determined as previously described (25). Briefly, the 92.1 and B16-F1 cells were seeded in 6-well plates at a cell density of $1 \times 10^{5}$ cells/well and $2 \times 10^{5}$ cells/well, respectively, and treated with either forskolin or argan oil at various concentrations and for different periods of time, as indicated in the figure legends. The MAP kinase inhibitor, PD98059 $(25 \mu \mathrm{M})$, or the PI3K/Akt inhibitors, wortmannin $(50 \mathrm{nM})$ and LY294002 $(20 \mu \mathrm{M})$, were incubated with the cells in the absence or presence of forskolin $(50 \mu \mathrm{M})$ for 48 h. Following incubation, the medium was removed, and the cells were mechanically detached and pelleted. Melanin in cell pellets was dissolved in $1 \mathrm{M} \mathrm{NaOH} / 10 \%$ DMSO by boiling for $1 \mathrm{~h}$. Determination of the melanin content was carried out by optical reading at $490 \mathrm{~nm}$ and the relative melanin quantity was normalized to the protein concentration of each sample, measured by BCA protein assay (BCA protein assay kit; cat. no. sc-202389; Santa Cruz Biotechnology, Inc.).

Western blot analysis. The cells were plated in $60 \mathrm{~mm}$ dishes at a cell density of $2 \times 10^{5}$ cells/dish and treated with either forskolin or argan oil at various concentrations and for different periods of time, as indicated in the figure legends. In some experiments, the MAP kinase inhibitor, PD98059 $(25 \mu \mathrm{M})$, or PI3K/Akt inhibitors, wortmannin $(50 \mathrm{nM})$ and LY294002 $(20 \mu \mathrm{M})$, were incubated with the cells in the absence or presence of forskolin for $48 \mathrm{~h}$. Following incubation, the cells were lysed in the dish by CHAPS buffer cell lysis ( $5 \mathrm{mM} \mathrm{MgCl}_{2}, 1 \mathrm{mM}$ EGTA, $100 \mathrm{mM}$ $\mathrm{NaCl}, 10 \%$ Glicerol, 1\% CHAPS, 25 mM Hepes, 1 mM sodium orthovanadate) and the protein concentration was determined by BCA protein assay. Western blot analysis was performed as previously described (26). The membranes were incubated with primary antibodies $\left(1: 1,000,4^{\circ} \mathrm{C}\right.$, overnight $)$ and then incubated with secondary antibodies rabbit anti-goat (sc-2768; Santa Cruz Biotechnology, Inc.), donkey anti-rabbit (NA934V; Amersham), sheep anti-mouse (NA931V; Amersham) (1:2,000, at room temperature for $1 \mathrm{~h}$ ). The immunocomplexes were detected by enhanced chemiluminescence reagent (ECL; GE Healthcare Life Sciences, Little Chalfont, UK). All blots were standardized for equal loading by actin monoclonal antibody staining.

Evaluation of tyrosinase and MITF gene expression. The 92.1 uveal melanoma cells were plated in $60 \mathrm{~mm}$ dishes at a density of $2 \times 10^{5}$ cells/dish and treated with 1/100 v/v argan oil 
$\mathbf{A}$
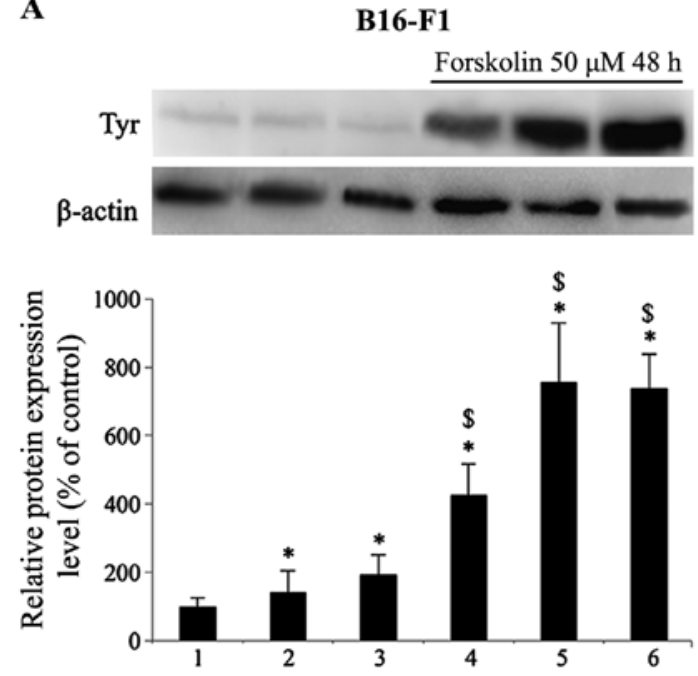

B
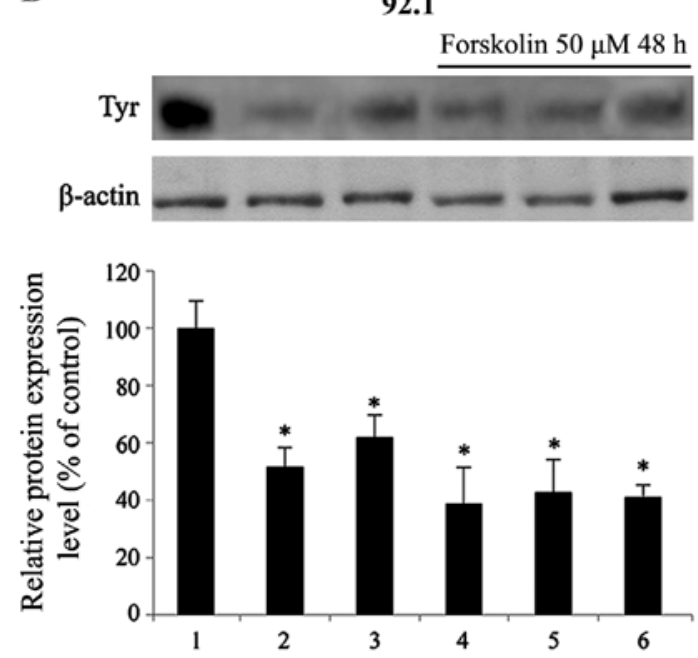

Figure 1. Tyrosinase protein expression in (A) B16-F1 mouse cutaneous melanoma cells and (B) 92.1 human uveal melanoma cells was determined by western blot analysis. The cells were incubated with $25 \mu \mathrm{M}$ of PD98059 (MEK inhibitor, preventing ERK1/2 phosphorylation) or a PI3K inhibitor mix (inhibiting Akt phosphorylation) made by wortmannin $(50 \mathrm{nM})$ and LY294002 $(20 \mu \mathrm{M})$ in the absence or presence of $50 \mu \mathrm{M}$ forskolin (adenylate cyclase direct activator) for $48 \mathrm{~h}$. Values are the means \pm SD from 3 independent experiments $(n=3)$ performed in triplicate. Statistically significant differences by one-way ANOVA and Tukey's post hoc test are indicated by symbols ( ${ }^{*} \mathrm{p}<0.05 \mathrm{vs}$. control; ${ }^{\$} \mathrm{p}<0.05$ vs. forskolin-treated cells). The loading control was assessed by using anti- $\beta$-actin antibody. Results are shown as a percentage of the control. The lanes and bars are labeled as follows: 1, control; 2, PD98059; 3, wortmannin plus LY294002; 4, forskolin; 5, forskolin plus PD98059; 6, forskolin plus wortmannin plus LY294002.

in complete culture medium for 3 days with daily changing of the emulsion. The cells were cultured for 2 more days in the absence of argan oil to examine the reversibility of the effect. Following incubation, RNA was extracted from the monolayer cells using TRIzol reagent (Thermo Fisher Scientific) according to the manufacturer's instruction and re-dissolved in $30 \mu \mathrm{l}$ RNase-free water (27). Reverse transcription-semiquantitative PCR was conducted as previously described. The RNA concentration and purity were estimated by optical density at 260 and $280 \mathrm{~nm}$ (28). First-strand cDNA was reverse transcribed in a $20 \mu \mathrm{l}$ reaction volume with
SuperScript III (Thermo Fisher Scientific). The PCR reactions were performed using Platinum PCR SuperScript (Thermo Fisher Scientific). Cycling parameters were initial denaturing, $94^{\circ} \mathrm{C}$ for $2 \mathrm{~min}$, denaturing, $94^{\circ} \mathrm{C}$ for $30 \mathrm{sec}$, annealing at specific temperature $\left(55-56^{\circ} \mathrm{C}\right)$ for $40 \mathrm{sec}$, extension $\left(72^{\circ} \mathrm{C}\right.$ for $30 \mathrm{sec}$ ), and a final extension step at $72^{\circ} \mathrm{C}$ for $5 \mathrm{~min}$. Specific primers for human MITF, tyrosinase and $\beta$-actin genes were used in semi-quantitative RT-PCR. A 92 bp product, using a forward primer (5'-AAGGCCAAGTGACACCAGCC-3') and reverse primer (5'-GAAACAGAGCAACGAGATGGG-3'), was amplified for human tyrosinase. A $116 \mathrm{bp}$ product, using a forward primer (5'-AAGTGAACGTGTTCGAGAGG-3') and reverse primer (5'-GATGATGCGGCTGTGATGG-3'), was amplified for MITF. The primers used for $\beta$-actin were forward, 5'-TAGACAAGATGGTGAAGG-3' and reverse, 5'-GCAGGGATGATGTTCTGG-3' and their amplification product was $650 \mathrm{bp}$.

Statistical analysis. The statistical significance between 2 groups was analyzed using the Student's t-test. One-way analysis of variance (ANOVA), followed by Tukey's post hoc test, was used to compare the means for the multiple groups. A p-value $<0.05$ was considered to indicate a statistically significant difference.

\section{Results}

Tyrosinase expression and melanin content in cutaneous and uveal melanoma cells: effects of specific modulators. Fig. 1 illustrates the response of B16-F1 murine cutaneous cells (Fig. 1A) and 92.1 human uveal melanoma cells (Fig. 1B) following $48 \mathrm{~h}$ of treatment with different compounds known to modulate melanogenesis and tyrosinase expression, namely the adenyl cyclase and PKA activator, forskolin (29), the mitogenactivated protein (MAP) kinase inhibitor, PD98059 (30), and the PI3K/Akt inhibitors, wortmannin and LY294002 (31), are known inducers of melanogenesis and tyrosinase expression in skin melanocytes. The results presented in Fig. 1A revealed that in the B16-F1 mouse cutaneous melanoma cells, tyrosinase expression in the presence of $25 \mu \mathrm{M}$ PD98059 and wortmannin $(50 \mathrm{nM}) / \mathrm{LY} 294002(20 \mu \mathrm{M})$ increased by 1.4- and 1.9- fold, respectively. The incubation of the B16-F1 cells in the presence of $50 \mu \mathrm{M}$ forskolin induced a greater increase in tyrosinase expression by 4.3 -fold in comparison to the control cells. Incubation with forskolin in the presence of PD98059 and wortmannin/LY294002 further increased tyrosinase protein expression by 1.7 -fold in comparison to the cells treated with forskolin alone.

Surprisingly, the expression of tyrosinase in the 92.1 human uveal melanoma cells (Fig. 1B) significantly decreased following incubation with PD98059 and wortmannin/LY294002 by 48 and $38 \%$, respectively, in comparison to the control cells. Incubation with forskolin induced a greater reduction in tyrosinase expression (by 61\%) in comparison to the control cells; this decrease was not further enhanced by the simultaneous presence of PD98059 and wortmannin/LY294002, indicating a differential regulation of enzyme expression in the B16-F1 cells and 92.1 cells.

The results presented in Fig. 2 basically confirmed the abovementioned results, using melanin as a marker of differentiation. 
$\mathbf{A}$

B16-F1
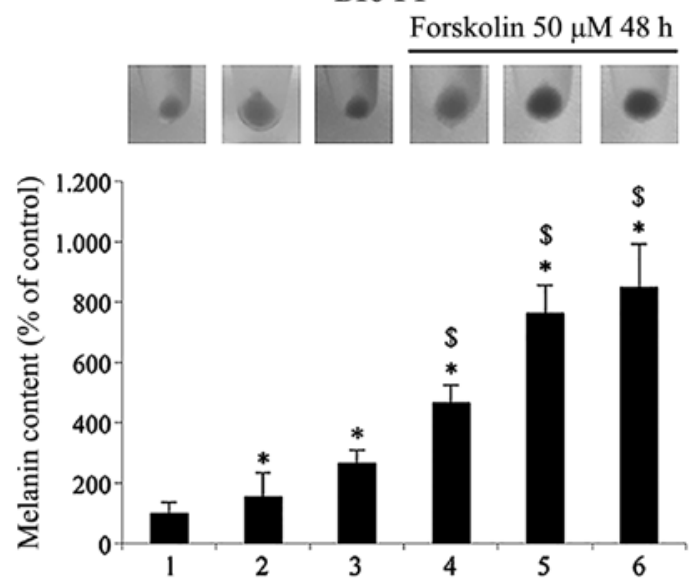

B

92.1

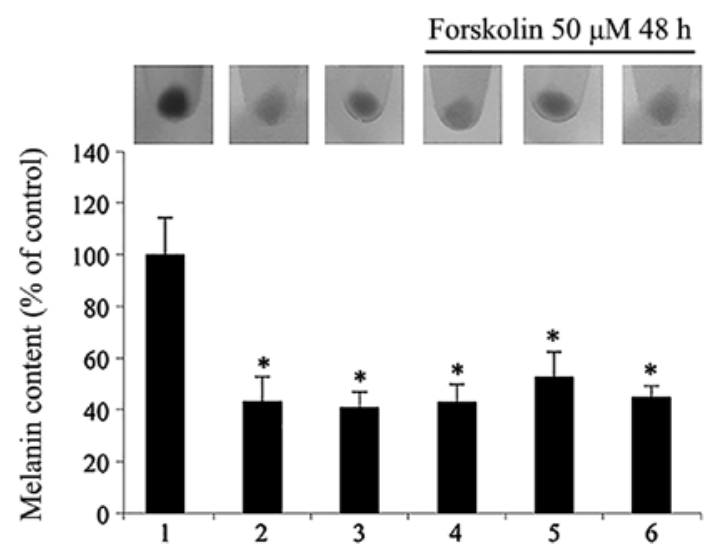

Figure 2. Determination of melanin content in (A) B16-F1 mouse cutaneous melanoma cells and (B) 92.1 human uveal melanoma cells. The cells were incubated with $25 \mu \mathrm{M}$ of PD98059 or wortmannin (50 nM) plus LY294002 $(20 \mu \mathrm{M})$ in the absence or presence of forskolin $50 \mu \mathrm{M}$ for $48 \mathrm{~h}$ and melanin content was measured. Values are the means \pm SD from 3 independent experiments $(n=3)$ performed in triplicate. Statistically significant differences by one-way ANOVA and Tukey's post hoc test are indicated by symbols ( ${ }^{*} \mathrm{p}<0.05$ vs. control cells, ${ }^{\$} \mathrm{p}<0.05$ vs. forskolin-treated cells). Results, normalized with protein content of each well, are expressed as a percentage of the control. The cell pellets, collected from the cells incubated with the compounds for the indicated periods of time, were photographed. The lanes and bars are labeled as follows: 1, control; 2, PD98059; 3, wortmannin plus LY294002; 4, forskolin; 5, forskolin plus PD98059; 6, forskolin plus wortmannin plus LY294002.

As shown in Fig. 2A, incubation of the B16-F1 mouse cutaneous melanoma cells with the adenyl cyclase activator, forskolin, increased melanin production by $>4$-fold. The inhibition of ERK1/2 and PI3K/Akt with the specific inhibitors increased the melanin content both in the absence (by 1.5- and 2.6- fold in comparison to the control cells) and in the presence of forskolin (by 1.6- and 1.8- fold in comparison to the forskolintreated cells). By contrast, in the 92.1 human uveal melanoma cells (Fig. 2B), the inhibition of ERK1/2 and PI3K/Akt led to a significant decrease in the melanin content in the absence of forskolin (57 and 59\%, respectively in comparison to the control cells). Treatment with forskolin alone decreased the melanin content by $57 \%$ in comparison to the control cells, and the inhibition of both ERK1/2 and PI3K/Akt in the forskolin-treated cells decreased the melanin content by 47 and 55\%, respectively.
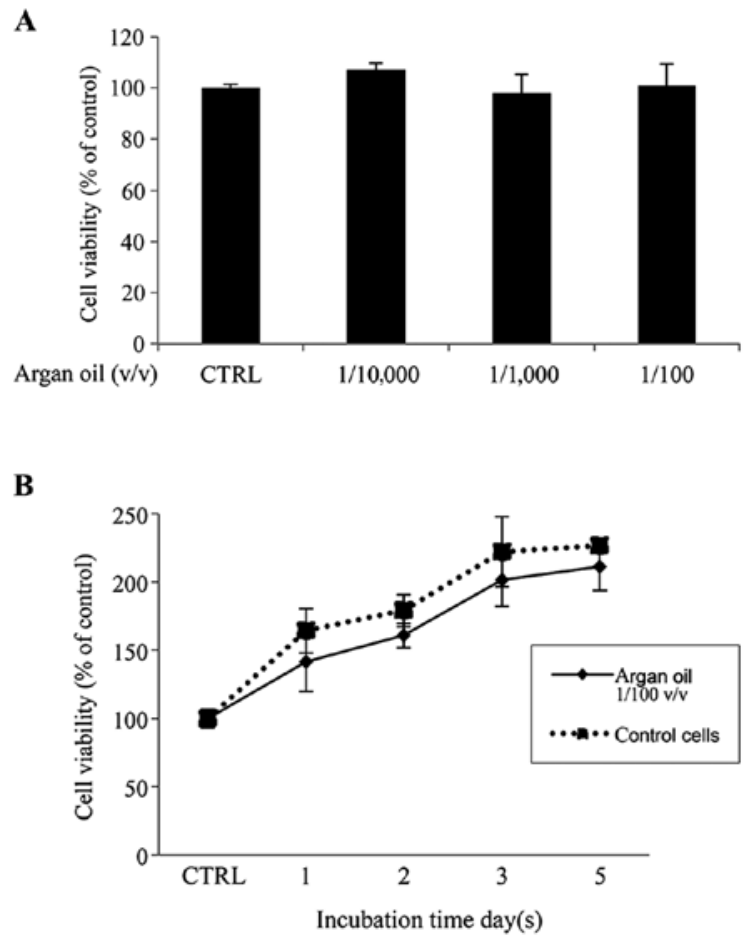

Figure 3. Effect of argan oil on 92.1 cell viability. (A) The cells were incubated in the absence (CTRL) or in presence of increasing concentrations of argan oil $(1 / 10,000-1 / 1,000-1 / 100 \mathrm{v} / \mathrm{v})$ for 5 days and cell viability was determined. (B) Cell growth curve at $1 / 100 \mathrm{v} / \mathrm{v}$ argan oil for 1,2, 3 and 5 days. Each condition had the appropriate control at the same time of incubation. No differences were observed in the control cells with different incubation times. Values are the means \pm SD from 3 independent experiments $(n=3)$ performed in triplicate. Results are shown as a percentage of the control.

Taken together, these data clearly indicate the differential regulation of tyrosinase expression by ERK1/2 and PI3K/Akt in the two melanoma cell lines of different origin.

Effect of argan oil on 92.1 cell viability. Cell viability following a 5-day exposure to argan oil fine emulsion in growth medium at 1/100,1/1,000 and 1/10,000 v/v dilution exerted no toxic effects (Fig. 3A). Therefore, the $1 / 100 \mathrm{v} / \mathrm{v}$ dilution was selected for use in the subsquent experiments. A cell growth curve at this dilution also exhibited no significant difference in cell viability between the untreated cells and cells treated for 1-5 days with argan oil (Fig. 3B).

Argan oil elicits a time-dependent decrease in tyrosinase protein and gene expression in 92.1 cells. To investigate the possible role of argan oil in melanogenesis, we evaluated tyrosinase expression in the 92.1 cells following incubation for 1, 2, 3 and 5 days with $1 \%$ argan oil. As shown in Fig. 4A, argan oil induced a decrease in tyrosinase protein expression progressing until day 3 , and then an increase after 5 days. In particular, a decrease of 71,81 , and $84 \%$ in comparison to the the control cells was observed following treatment of the cells with $1 \%$ argan oil for 1,2 and 3 days, respectively. After 5 days, an increase in tyrosinase expression (a recovery of 2.9-fold compared to day 3) was observed in comparison to the shorter incubation periods, while maintaining a $47 \%$ reduction, in comparison to the control cells. Semi-quantitative RT-PCR (Fig. 4B) revealed a similar time-dependent variation 
A

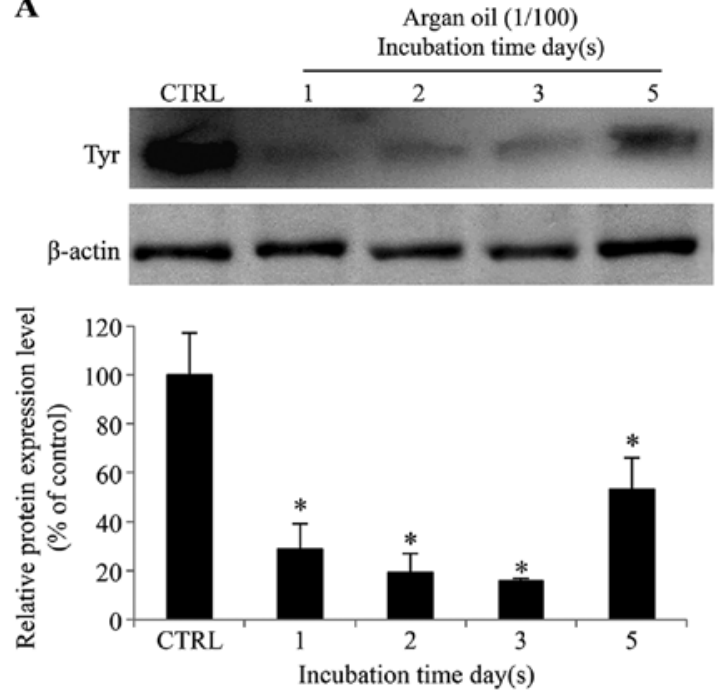

B
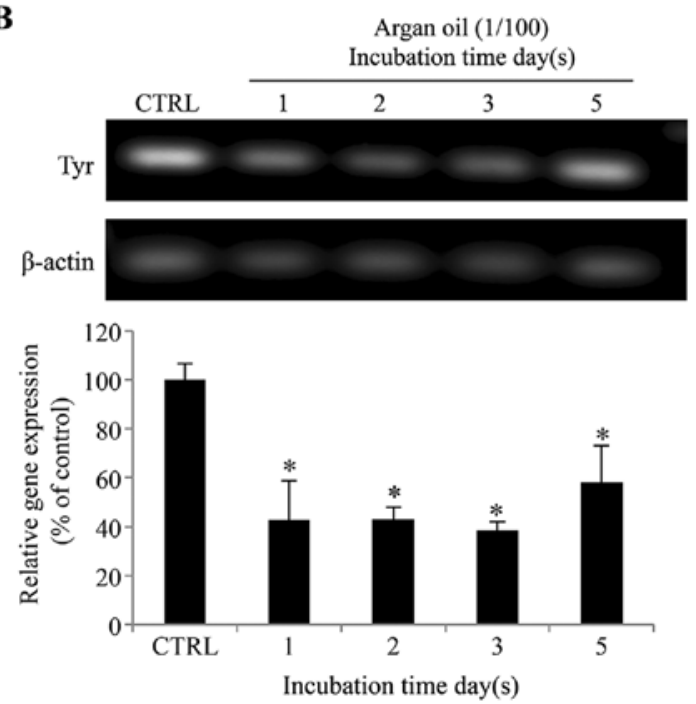

Figure 4. Effect of argan oil on tyrosinase expression in 92.1 cells. (A) 92.1 cells were incubated in the absence (CTRL) or presence of 1/100 v/v argan oil for 1 , 2, 3 and 5 days and tyrosinase protein expression was determined by western blot analysis. The loading control was assessed by using anti- $\beta$-actin antibody. (B) Effect of argan oil on tyrosinase mRNA expression. 92.1 human uvea melanoma cells were incubated in absence (CTRL) or presence of 1/100 v/v argan oil for 1, 2, 3 and 5 days prior to total RNA extraction. Each condition had the appropriate control at the same time of incubation. No differences were observed in control cells with different incubation times. Values are the means \pm SD from3three independent experiments $(n=3)$ performed in triplicate. Statistically significant differences by one-way ANOVA and Tukey's post hoc test are indicated by asterisk (" $\mathrm{p}<0.05$ vs. control cells). Results are shown as a percentage of the control.

in tyrosinase gene expression, with a reduction of $61,59,63$ and $48 \%$ after 1,2, 3 and 5 days, respectively, in comparison to the control cells.

Argan oil treatment reduces the melanin content in 92.1 cells. In agreement with the data already obtained, treatment of the 92.1 cells with argan oil also indcued a significant and progressive decrease in melanin content up until day 3 of stimulation $(36,48$ and $57 \%$ of reduction after 1, 2 and 3 days, respectively, in comparison to the control cells) with a partial recovery after 5 days of treatment (35\% of reduction at day 5

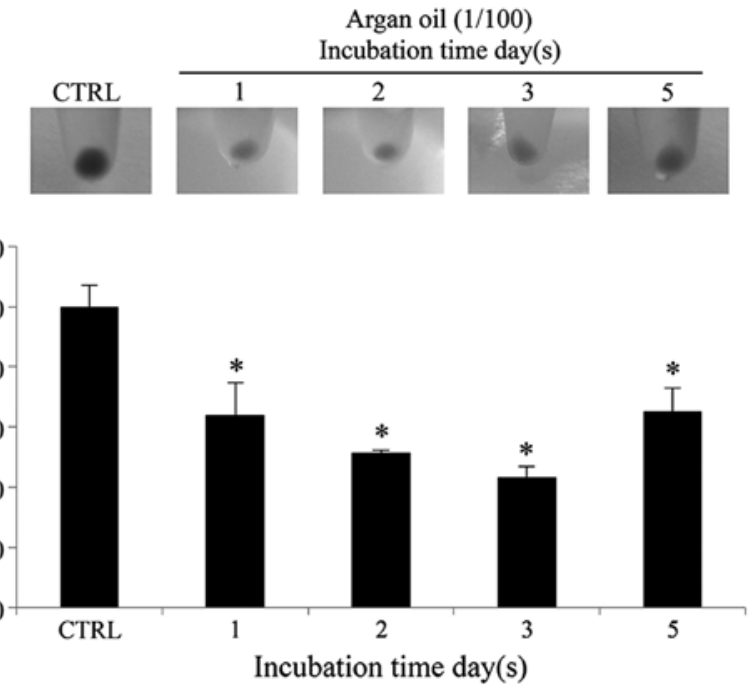

Figure 5. Depigmenting effect of argan oil on 92.1 cells. The melanin content in the 92.1 cells was measured following treatment with $1 / 100 \mathrm{v} / \mathrm{v}$ argan oil for 1, 2, 3 and 5 days, as described in the Material and methods. Each condition had the appropriate control at the same time of incubation. No differences were observed in the control cells with different incubation times. Values are the means \pm SD from 3 independent experiments $(n=3)$ performed in triplicate. Statistically significant differences by one-way ANOVA and Tukey's post hoc test are indicated by asterisk ( ${ }^{*} \mathrm{p}<0.05 \mathrm{vs}$. control cells). Results, normalized with protein content of each well, are expressed as a percentage of the control. The cell pellets, collected from the cells incubated with argan oil for the indicated time, were photographed.

in comparison with the control cells) (Fig. 5). The different gray intensity of the cell pellets, just before their lysis in hot $\mathrm{NaOH}$ for the detection of melanin content, clearly illustrates the depigmenting effect following treatment with argan oil (Fig. 5).

Argan oil promotes MITF degradation, decreases MITF gene expression and impairs ERK1/2 and AKT phosphorylation in 92.1 cells. Due to the observed effects of argan oil on melanin biosynthesis and tyrosinase expression, we investigated the expression of the transcription factor, MITF.

As shown in Fig. 6A, as already observed for tyrosinase expression and melanin production, treatment with argan oil progressively increased the phosphorylation and further proteasome the degradation (10) of MITF at Ser73 (20\% at day $1,120 \%$ at day 2 and $160 \%$ at day 3) with a partial recovery following treatment for 5 days (20\% increase in comparison to the control cells). Argan oil also decreased MITF gene expression (Fig. 6B). However, a different trend was observed in this case; this involved a sharp reduction following incubation with argan oil for 1 and 2 days, followed by a progressive recovery following incubation for 3 and 5 days (90, 74, 54 and 35\% of reduction after 1, 2, 3 and 5 days, respectively, in comparison to the control cells).

Given that specific inhibitors of ERK1/2 and PI3K/Akt phosphorylation decreased tyrosinase expression and the melanin content in 92.1 cells, we wished to determine whether argan oil can influence ERK1/2 and PI3K/Akt activation and expression.

As shown in Fig. 7A, p-ERK1/2 and ERK protein expression levels were examined. As expected, $1 \%$ argan oil reduced 
A

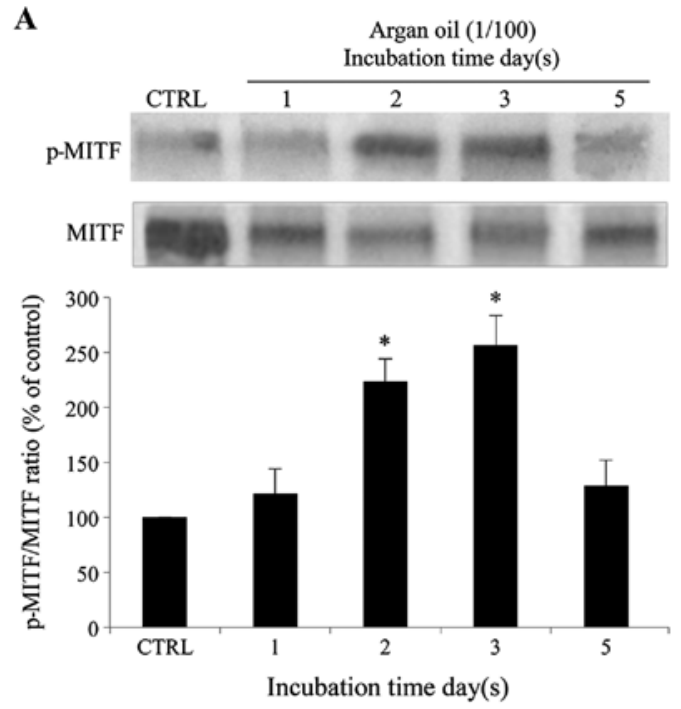

B
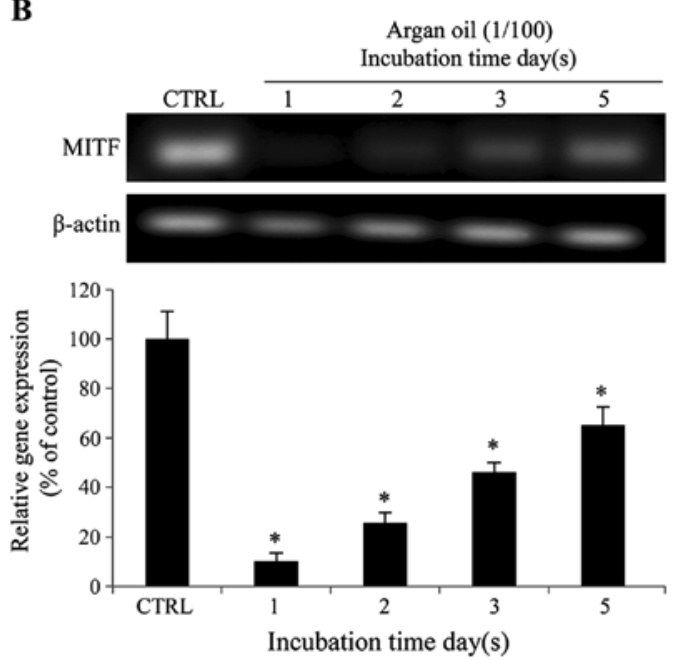

Figure 6.Effect of argan oil on MITFexpression in 92.1 cells. (A) Phosphorylated MITF at Ser73 and total MITF proteins were determined by western blot analysis. 92.1 human uveal melanoma cells were incubated in absence (CTRL) or in presence of $1 / 100 \mathrm{v} / \mathrm{v}$ argan oil for $1,2,3$ and 5 days. The loading control was assessed by using anti- $\beta$-actin antibody. (B) MITF mRNA expression. 92.1 cells were incubated in the absence (CTRL) or in the presence of $1 / 100 \mathrm{v} / \mathrm{v}$ argan oil for 1,2,3 and 5 days prior to total RNA extraction. Each condition had the appropriate control at the same time of incubation. No differences were observed in the control cells with different incubation times. Values are the means \pm SD from 3 independent experiments $(n=3)$ performed in triplicate. Statistically significant differences by one-way ANOVA and Tukey's post hoc test are indicated by an asterisk ( $\mathrm{p}<0.05$ vs. control cells). Results are shown as percentage of control.

ERK1/2 phosphorylation by $75,70,75$ and $35 \%$ following incubation of the 92.1 cells for 1,2, 3 and 5 days, respectively, compared to the control cells.

As shown in Fig. 7B, p-Akt and Akt protein expression levels were also examined. Incubation of the 92.1 cells with $1 \%$ argan oil induced a decrease in the levels of p-Akt by 62 , 63, 80 and $33 \%$ following incubation for 1,2, 3 and 5 days, in comparison to the control cells.

\section{Discussion}

The human iris contains two types of pigmented cells, epithelial cells and melanocytes. Iris pigmented epithelial cells are located
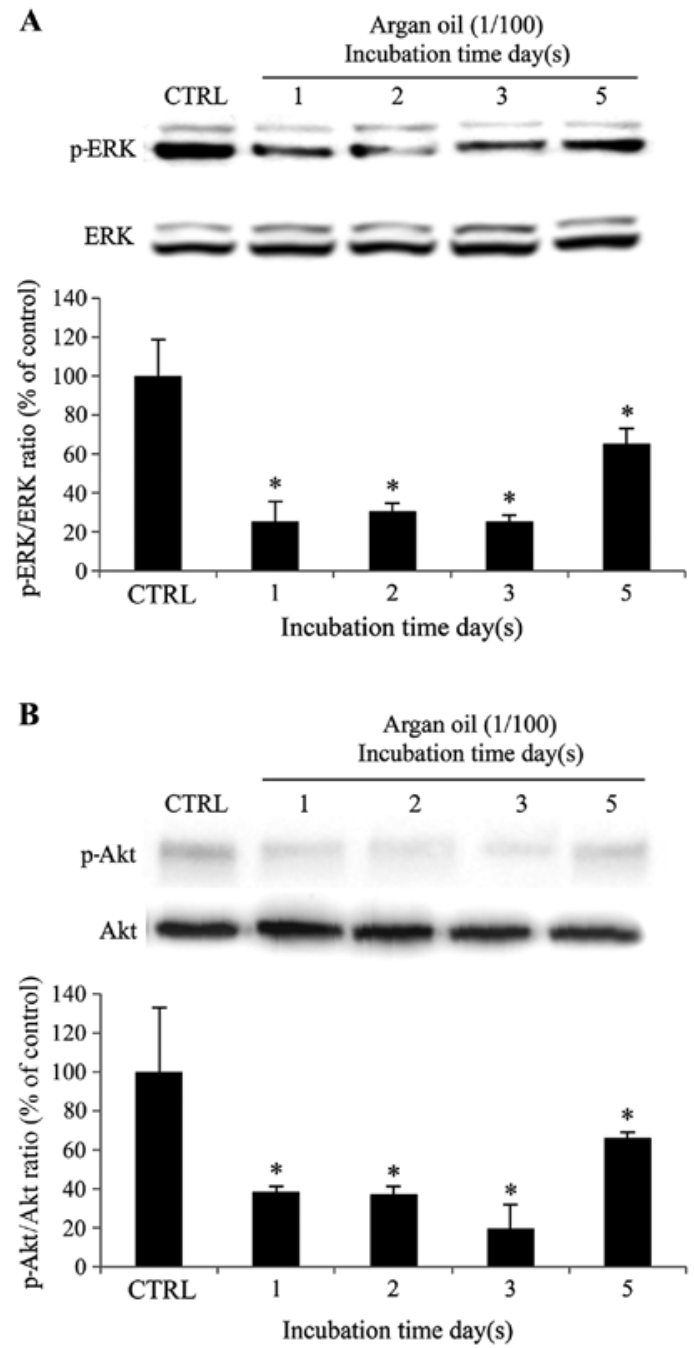

Figure 7. Effect of argan oil on ERK1/2 and Akt expression/activation. (A) The expression of p-ERK and total ERK and (B) the expression of p-Akt and total Akt were determined by western blot analysis. Densitometric values are also reported. 92.1 human uveal melanoma cells were incubated in absence (CTRL) or in presence of 1/100 v/v argan oil for 1,2, 3 and 5 days. Each condition had the appropriate control at the same time of incubation. No differences were observed in the control cells with different incubation times. Values are the means \pm SD from 3 independent experiments $(n=3)$ performed in triplicate. Statistically significant differences by one-way ANOVA and Tukey's post hoc test are indicated by an asterisk ( ${ }^{*} \mathrm{p}<0.05$ vs. control cells). Results are shown as a percentage of the control.

in a double layer at the posterior surface of the iris, and do not produce melanin in vitro (32). Their melanin content does not vary significantly between irises of different colors, and thus it is believed that they play a minor role in iris color variations (33-35). Uveal melanocytes are dispersed in the iris stroma and do produce melanin in vitro (36); their melanin content varies in different colored irises (both in vivo and in vitro), and thus that they represent the main factor in determining iris color (33-36). Ocular pigmentation in humans is assumed to stabilize past infancy; however, a study on eye color changes in a group of twin pairs, enrolled in the Louisville Twin Study, revealed that the iris pigmentation was variable throughout adolescence in $10-15 \%$ of subjects (37). The uneven darkening of iris color is a well-known side-effect of glaucoma treatment with prostaglandins or prostaglandin analogues, such as isopropyl unoprostone or latanoprost $(15,38)$. Thus, the changes 
in iris color during a human lifetime may be more frequent than supposed both for physiological and pathological events.

Uveal and cutaneous melanocytes have different functions. Cutaneous melanocytes continuously synthesize and transfer melanin to keratinocytes, in a juxtacrine-regulated interaction in which keratinocytes respond secreting growth factors for melanocytes (39). Similar to cutaneous melanocytes, conjunctival melanocytes transfer melanin to conjunctival epithelial cells (40). Finally, ocular albinism depigmentation occurs in the eye, but not in the skin (41), indicating that melanogenesis in uveal and cutaneous melanocytes involves different pathways, starting from the lack of response of uveal melanocytes to $\mathrm{MSH}$, the melanocyte stimulating hormone, the main orchestrator of cutaneous melanogenesis (14).

Considering the pivotal role of the ERK1/2 and PI3K/Akt pathways in the regulation of cutaneous melanogenesis (42), we set out to explore the role of these two pathways in the regulation of ocular melanogenesis by using molecules able to interfere with the regulation of melanogenesis. We used B16-F1 mouse cutaneous melanoma cells and 92.1 human uveal melanoma cells, both with a detectable melanin content (43).

Our results revealed that ERK1/2 and PI3K-Akt played an opposing role in the regulation of melanogenesis in the iris melanoma cells in comparison to the cutaneous melanoma cells. Surprisingly, specific inhibitors of both kinases significantly decreased tyrosinase protein expression and melanin content in the 92.1 cells, but not in the B16-F1 cells, where significant increases were observed. Even more surprisingly, in the presence of forskolin, we did not observe an increase (such as in the B16-F1 cells), but rather a marked decrease in tyrosinase protein expression and melanin content in the 92.1 cells.

Argan oil is already widely used for cosmetic and medicinal purposes and one in vitro study showed its depigmenting activity on B16-F1 cells (17). Moreover, another in vitro study showed its ability to reduce ERK1/2 and Akt phosphorylation in the HTC liver cell line (44). For these reasons, we used it in our cellular model in order to modulate ocular melanogenesis.

Argan oil exhibited a time-dependent depigmenting activity, with a decrease in both tyrosinase gene and protein expression, and in the melanin content, an increase in the phosphorylation of MITF at Ser73, probably leading to its ubiquitination and degradation, and a decrease in MITF gene expression. Moreover, argan oil decreased ERK1/2 and Akt phosphorylation and, taking into account our results, this may be the mechanism through which argan oil exerts its depigmenting effects on human uveal melanoma cells.

The understanding of the molecular mechanisms which regulate uveal melanogenesis may have significance in the treatment of several eye diseases. It has been observed that the development of certain eye diseases may be related to exposure to ultraviolet and visible light. In this regard, a population-based study demonstrated that exposure to sunlight may be associated with age-related macular degeneration, a greater incidence in blue irises than in brown irises patients (45).

For these reasons, the study of ocular melanogenesis mechanisms and the identification of molecules able to modulate it, similarly to what has been done for cutaneous melanogenesis, may have both cosmetic and medical implications. Further studies are therefore warranted in order to fully determine the mechanisms of ocular melanogenesis.

\section{References}

1. Plonka PM, Passeron T, Brenner M, Tobin DJ, Shibahara S, Thomas A, Slominski A, Kadekaro AL, Hershkovitz D, Peters E, et al: What are melanocytes really doing all day long...? Exp Dermatol 18: 799-819, 2009.

2. Tachibana M: Sound needs sound melanocytes to be heard Pigment Cell Res 12: 344-354, 1999.

3. Brito FC and Kos L: Timeline and distribution of melanocyte precursors in the mouse heart. Pigment Cell Melanoma Res 21: 464-470, 2008.

4. Hu DN, Simon JD and Sarna T: Role of ocular melanin in ophthalmic physiology and pathology. Photochem Photobiol 84: 639-644, 2008

5. Randhawa M, Huff T, Valencia JC, Younossi Z, Chandhoke V, Hearing VJ and Baranova A: Evidence for the ectopic synthesis of melanin in human adipose tissue. FASEB J 23: 835-843, 2009.

6. Suzuki I, Cone RD, Im S, Nordlund J and Abdel-Malek ZA: Binding of melanotropic hormones to the melanocortin receptor MC1R on human melanocytes stimulates proliferation and melanogenesis. Endocrinology 137: 1627-1633, 1996.

7. Olivares $\mathrm{C}$ and Solano F: New insights into the active site structure and catalytic mechanism of tyrosinase and its related proteins. Pigment Cell Melanoma Res 22: 750-760, 2009.

8. Costin GE and Hearing VJ: Human skin pigmentation: Melanocytes modulate skin color in response to stress. FASEB J 21: 976-994, 2007.

9. Oka M, Kageyama A, Fukunaga M, Bito T, Nagai $\mathrm{H}$ and Nishigori C: Phosphatidylinositol 3-kinase/Akt-dependent and -independent protection against apoptosis in normal human melanocytes. J Invest Dermatol 123: 930-936, 2004.

10. Hemesath TJ, Price ER, Takemoto C, Badalian T and Fisher DE: MAP kinase links the transcription factor Microphthalmia to c-Kit signalling in melanocytes. Nature 391: 298-301, 1998.

11. Slominski A, Tobin DJ, Shibahara S and Wortsman J: Melanin pigmentation in mammalian skin and its hormonal regulation. Physiol Rev 84: 1155-1228, 2004.

12. Bae JS, Han M, Yao C and Chung JH: Chaetocin inhibits IBMX-induced melanogenesis in B16F10 mouse melanoma cells through activation of ERK. Chem Biol Interact 245: 66-71 2016.

13. Jeong HS, Gu GE, Jo AR, Bang JS, Yun HY, Baek KJ, Kwon NS, Park KC and Kim DS: Baicalin-induced Akt activation decreases melanogenesis through downregulation of microphthalmia-associated transcription factor and tyrosinase. Eur J Pharmacol 761: 19-27, 2015.

14. Li L, Hu DN, Zhao H, McCormick SA, Nordlund JJ and Boissy RE: Uveal melanocytes do not respond to or express receptors for $\alpha$-melanocyte-stimulating hormone. Invest Ophthalmol Vis Sci 47: 4507-4512, 2006.

15. Hu DN, Stjernschantz J and McCormick SA: Effect of prostaglandins $\mathrm{A}_{2}, \mathrm{E}_{1}, \mathrm{~F}_{2}$ and latanoprost on cultured human iridal melanocytes. Exp Eye Res 70: 113-120, 2000.

16. Hamid MA, Sarmidi MR and Park CS: Mangosteen leaf extract increases melanogenesis in B16F1 melanoma cells by stimulating tyrosinase activity in vitro and by up-regulating tyrosinase gene expression. Int J Mol Med 29: 209-217, 2012.

17. Li X, Guo L, Sun Y, Zhou J, Gu Y and Li Y: Baicalein inhibits melanogenesis through activation of the ERK signaling pathway. Int J Mol Med 25: 923-927, 2010.

18. Guo H, Yang K, Deng F, Xing Y, Li Y, Lian X and Yang T: Wnt3a inhibits proliferation but promotes melanogenesis of melan-a cells. Int J Mol Med 30: 636-642, 2012.

19. Lv N, Koo JH, Yoon HY, Yu J, Kim KA, Choi IW, Kwon KB, Kwon KS, Kim HU, Park JW, et al: Effect of Angelica gigas extract on melanogenesis in B16 melanoma cells. Int J Mol Med 20: 763-767, 2007.

20. Huang HC, Lin H and Huang MC: The lactoferricin B-derived peptide, LfB17-34, induces melanogenesis in B16F10 cells. Int J Mol Med 39: 595-602, 2017.

21. Solano F, Briganti S, Picardo M and Ghanem G: Hypopigmenting agents: An updated review on biological, chemical and clinical aspects. Pigment Cell Res 19: 550-571, 2006.

22. Villareal MO, Kume S, Bourhim T, Bakhtaoui FZ, Kashiwagi K, Han J, Gadhi C and Isoda H: Activation of MITF by argan oil leads to the inhibition of the tyrosinase and dopachrome tautomerase expressions in B16 murine melanoma cells. Evid Based Complement Alternat Med 2013: 340107, 2013.

23. Anfuso CD, Motta C, Giurdanella G, Arena V, Alberghina M and Lupo G: Endothelial PKCa-MAPK/ERK-phospholipase A pathway activation as a response of glioma in a triple culture model. A new role for pericytes? Biochimie 99: 77-87, 2014. 
24. Anfuso CD, Giurdanella G, Motta C, Muriana S, Lupo G, Ragusa N and Alberghina M: PKC $\alpha$-MAPK/ERK-phospholipase $\mathrm{A}_{2}$ signaling is required for human melanoma-enhanced brain endothelial cell proliferation and motility. Microvasc Res 78: 338-357, 2009.

25. Rusciano D, Lorenzoni P, Lin S and Burger MM: Hepatocyte growth factor/scatter factor and hepatocytes are potent downregulators of tyrosinase expression in B16 melanoma cells. J Cell Biochem 71: 264-276, 1998.

26. Lupo G, Anfuso CD, Ragusa N, Tirolo C, Marchetti B, Gili E, La Rosa $\mathrm{C}$ and Vancheri C: Activation of cytosolic phospholipase $\mathrm{A}_{2}$ and 15-lipoxygenase by oxidized low-density lipoproteins in cultured human lung fibroblasts. Biochim Biophys Acta 1771: 522-532, 2007

27. Giurdanella G, Anfuso CD, Olivieri M, Lupo G, Caporarello N, Eandi CM, Drago F, Bucolo C and Salomone S: Aflibercept, bevacizumab and ranibizumab prevent glucose-induced damage in human retinal pericytes in vitro, through a $\mathrm{PLA}_{2} / \mathrm{COX}-2 / \mathrm{VEGF}-\mathrm{A}$ pathway. Biochem Pharmacol 96: 278-287, 2015.

28. Scuderi MR, Anfuso CD, Lupo G, Motta C, Romeo L, Guerra L, Cappellani A, Ragusa N, Cantarella G and Alberghina M: Expression of $\mathrm{Ca}^{2+}$-independent and $\mathrm{Ca}^{2+}$-dependent phospholipases $\mathrm{A}_{2}$ and cyclooxygenases in human melanocytes and malignant melanoma cell lines. Biochim Biophys Acta 1781: 635-642, 2008

29. Cheli Y, Luciani F, Khaled M, Beuret L, Bille K, Gounon P, Ortonne JP, Bertolotto $\mathrm{C}$ and Ballotti R: $\alpha \mathrm{MSH}$ and cyclic AMP elevating agents control melanosome $\mathrm{pH}$ through a protein kinase A-independent mechanism. J Biol Chem 284: 18699-18706, 2009

30. Englaro W, Bertolotto C, Buscà R, Brunet A, Pagès G, Ortonne JP and Ballotti R: Inhibition of the mitogen-activated protein kinase pathway triggers B16 melanoma cell differentiation. J Biol Chem 273: 9966-9970, 1998.

31. Hah YS, Cho HY, Lim TY, Park DH, Kim HM, Yoon J, Kim JG, Kim CY and Yoon TJ: Induction of melanogenesis by rapamycin in human MNT-1 melanoma cells. Ann Dermatol 24: 151-157, 2012.

32. Hu DN, Ritch R, McCormick SA and Pelton-Henrion K: Isolation and cultivation of human iris pigment epithelium. Invest Ophthalmol Vis Sci 33: 2443-2453, 1992.

33. Eagle RC Jr: Iris pigmentation and pigmented lesions: An ultrastructural study. Trans Am Ophthalmol Soc 86: 581-687, 1988.
34. Imesch PD, Bindley CD, Khademian Z, Ladd B, Gangnon R, Albert DM and Wallow IH: Melanocytes and iris color. Electron microscopic findings. Arch Ophthalmol 114: 443-447, 1996.

35. Wilkerson CL, Syed NA, Fisher MR, Robinson NL, Wallow IH and Albert DM: Melanocytes and iris color. Light microscopic findings. Arch Ophthalmol 114: 437-442, 1996.

36. Hu DN: Regulation of growth and melanogenesis of uveal melanocytes. Pigment Cell Res 13 (Suppl 8): 81-86, 2000.

37. Bito LZ, Matheny A, Cruickshanks KJ, Nondahl DM and Carino OB: Eye color changes past early childhood. The Louisville Twin Study. Arch Ophthalmol 115: 659-663, 1997.

38. Wistrand PJ, Stjernschantz J and Olsson K: The incidence and time-course of latanoprost-induced iridial pigmentation as a function of eye color. Surv Ophthalmol 41 (Suppl 2): S129-S138, 1997.

39. Seiberg M: Keratinocyte-melanocyte interactions during melanosome transfer. Pigment Cell Res 14: 236-242, 2001.

40. Hu DN, McCormick SA, Seedor JA, Ritterband DC and Shah MK: Isolation, purification and cultivation of conjunctival melanocytes. Exp Eye Res 84: 655-662, 2007.

41. Bassi MT, Schiaffino MV, Renieri A, De Nigris F, Galli L, Bruttini M, Gebbia M, Bergen AA, Lewis RA and Ballabio A: Cloning of the gene for ocular albinism type 1 from the distal short arm of the X chromosome. Nat Genet 10: 13-19, 1995.

42. Kim HJ, Kim IS, Dong Y, Lee IS, Kim JS, Kim JS, Woo JT and Cha BY: Melanogenesis-inducing effect of cirsimaritin through increases in microphthalmia-associated transcription factor and tyrosinase expression. Int J Mol Sci 16: 8772-8788, 2015.

43. Onken MD, Li J and Cooper JA: Uveal melanoma cells utilize a novel route for transendothelial migration. PLoS One 9: e115472, 2014.

44. Samane S, Noël J, Charrouf Z, Amarouch H and Haddad PS: Insulin-sensitizing and anti-proliferative effects of Argania spinosa seed extracts. Evid Based Complement Alternat Med 3: 317-327, 2006.

45. Mitchell P, Smith W and Wang JJ: Iris color, skin sun sensitivity, and age-related maculopathy. The Blue Mountains Eye Study. Ophthalmology 105: 1359-1363, 1998 